\title{
REFORMA E RESISTÊNCIA: IMPACTOS ESTRUTURAIS DAS DITADURAS CIVIL-MILITARES BRASILEIRA (1964 - 1985) E CHILENA (1973 - 1990) NAS UNIVERSIDADES PÚBLICAS
}

\author{
REFORM AND RESISTANCE: THE STRUCTURAL IMPACTS OF BRAZILIAN AND \\ CHILEAN CIVIL-MILITARY DICTATORSHIPS ON PUBLIC UNIVERSITIES
}

\author{
Cecília Brancher de Oliveira ${ }^{1}$ \\ Universidade Federal de Santa Catarina, Florianópolis (SC), Brasil
}

\begin{abstract}
Resumo Este artigo visa compreender de que maneira as ditaduras civil-militares brasileiras (1964-1985) e chilena (1973-1990) modificaram o ensino público superior e a estrutura universitária dos respectivos países. Para isso, o artigo divide-se em quatro partes. A primeira faz um resgate dos movimentos prévios pela democratização e reforma do ensino superior. A segunda explora o projeto de educação superior com viés neoliberal implementado pelas ditaduras do Cone Sul. A terceira e a quarta partes descrevem e analisam a implementação de políticas e legislação voltadas à educação superior do Brasil e do Chile.
\end{abstract}

Palavras-chave: Ditadura civil-militar; ensino superior; Universidade pública; reforma universitária; educação.

ABSTRACT This article aims to understand how did the Brazilian and Chilean civil-military dictatorships manage to transform the higher education system and the structure of the public universities. Thus, this article is divided into four sections. The first section presents the social mobilization pro-democratization and higher education system reforms before the dictatorships. The second section explores the adoption of a neoliberal project for public higher education. Finally, the third and fourth sections describe and analyze the implementation of policies and legislation in public higher education during the dictatorships.

Keywords: Civil-military dictatorship; higher education; public University; University reform; education.

\section{INTRODUÇÃO}

As ditaduras civil-militares no Brasil (1964-1985) e no Chile (1973-1990) implementaram políticas educacionais voltadas ao ensino superior que impactaram profundamente a estrutura das universidades e a concepção de educação como um direito social, que vinha sendo coletivamente construída durante a década de 1960. Orientadas para atender aos interesses da elite política dominante, as políticas públicas dos períodos ditatoriais foram

\footnotetext{
${ }^{1}$ Graduanda em Relações Internacionais pela Universidade Federal de Santa Catarina (UFSC).
} 
marcadas pela influência de fatores internos e externos em sua concepção, no sentido de garantir a manutenção hegemônica do poder das classes dominantes e do capital internacional.

A educação, como campo de disputa política e social, mobilizou diversos setores da sociedade em períodos históricos distintos. Seja no início da década de 1960, através do debate sobre a reformulação dos sistemas de ensino superior público e a chamada "reforma universitária", cuja inspiração advinha do Manifesto de Córdoba de 1918. Ou no fim dos anos 1960 e durante a década de 1970, quando a luta pela democratização e universalização do ensino superior público foi suplantada pela política educacional imposta pelos governos ditatoriais, tanto no Brasil, quanto no Chile. As ditaduras civil-militares interromperam o processo de debate acerca da função da universidade pública, já bastante avançado no Chile governado por Salvador Allende e em vias de construção no governo de João Goulart no Brasil, e substituíramno por uma série de preceitos influenciados pela conjuntura política global, e por interferência direta dos Estados Unidos. Além das práticas repressivas e das sucessivas violações de direitos humanos que ocorreram também dentro do ambiente universitário, os governos ditatoriais brasileiro e chileno redirecionaram as políticas educacionais, alinhando-as aos interesses dos grupos sociais dominantes. O objetivo central deste artigo é entender como essas reformas aconteceram e quais foram as principais mudanças de rumo do ensino superior público no Brasil e no Chile com relação ao período pré-ditatorial.

Como veremos adiante, o projeto político de reestruturação do ensino superior das ditaduras brasileira e chilena teve algumas semelhanças, ainda que, no Chile, os efeitos a longo prazo tenham sido mais profundos e definitivos. Na primeira parte deste artigo, serão apresentados os antecedentes históricos que levaram à realização de importantes movimentos pela reforma universitária na América Latina durante a década de 1960. Posteriormente, será abordado o projeto político das ditaduras do Cone Sul para a educação superior. E, finalmente, será realizada uma análise sobre os casos brasileiro e chileno, através da apresentação das leis e decretos que reestruturaram o sistema público superior e, também, dos impactos das práticas repressivas e da contenção ao movimento estudantil universitário. 


\title{
2 ANTECEDENTES HISTÓRICOS: O MANIFESTO DE CÓRDOBA E A DÉCADA DE
} 1960

\begin{abstract}
A juventude já não pede. Exige que se reconheça o direito de exteriorizar esse pensamento próprio nos corpos universitários por meio de seus representantes.

Está cansada de suportar os tiranos. Se foi capaz de realizar uma revolução nas consciências, não pode desconhecer-se a capacidade de intervir no governo de sua própria casa. A juventude universitária de Córdoba, por meio de sua federação, saúda os companheiros da América toda e os incita a colaborar na obra de liberdade que se inicia. $^{2}$
\end{abstract}

O Manifesto de Córdoba de 1918, escrito por estudantes da Federación Universitaria de Córdoba, na Argentina, é considerado por muitos como um marco na transformação da Universidade latino-americana. Segundo José Alves de Freitas Neto (p. 65, 2011), a Universidade Nacional de Córdoba (UNC) no início do século XX era uma instituição conservadora que preservava características do período colonial. Nesse sentido, a motivação estudantil era construir um modelo de universidade para e a partir da Argentina, ou da própria América Latina.

Através da denúncia do caráter eclesiástico e aristocrático da estrutura universitária da UNC e da educação superior latino-americana, os estudantes propuseram, então, um novo modelo de Universidade, no qual o corpo discente seria um ator social central. As reivindicações principais que se seguiram ao manifesto foram: a coparticipação de professores e estudantes na estrutura administrativa; a autonomia política, docente e administrativa da Universidade; a extinção da cátedra vitalícia; a eleição de dirigentes por assembleias compostas de professores, estudantes e egressos; a gratuidade do ensino e democratização da universidade; a seleção de professores por meio de concursos públicos; o fortalecimento da função social da Universidade, entre outras.

Assim como o Manifesto de Córdoba, a década de 1960 representou um segundo momento importante para o ensino superior latino americano. Em distintas partes do mundo, esta foi a década de florescimento de diversos movimentos revolucionários. O movimento estudantil, não só brasileiro como também chileno, foi fortemente influenciado pelo contexto de reestruturação global do pós-Segunda Guerra Mundial e o início da Guerra Fria. Na América Latina, a Revolução Cubana em 1959 foi também propulsora da emergência reivindicativa e

\footnotetext{
${ }^{2}$ FEDERACIÓN UNIVERSITARIA DE CÓRDOBA. La juventud argentina de Córdoba a los hombres libres de Sudamérica [Manifiesto de Córdoba]. Argentina, junho de 1918.
} 
questionadora do movimento estudantil universitário, ainda marcado pelo impulso inicial gerado pelo Manifesto de Córdoba.

No Chile, a década de 1960 foi marcada pelas greves e ocupações universitárias, pela luta por um aprofundamento da democratização e universalidade do acesso ao ensino superior. O movimento pela Reforma Universitária foi a expressão de uma ampla tendência cultural e política em direção ao aprofundamento da democracia chilena. "A reforma iniciou como um grande movimento pela transformação dos programas de estudo, pela mudança substancial nas estruturas de poder na Universidade, pela aproximação da Universidade com o povo" (MARTÍNEZ, 1988, p. 167, tradução nossa). Assim como a UNC, as universidades chilenas eram elitistas em sua composição social, além de contarem com uma representação estudantil mínima na rígida e autoritária estrutura universitária.

O movimento pela reforma universitária no Chile ocorreu durante o governo de Frei Montalva (1964-1970), do partido Democracia Cristiana (DC), considerado "timidamente" reformista, mas que realizou uma reforma agrária e permitiu a organização sindical de trabalhadores e camponeses. Posteriormente, já no ano de 1970, a eleição do candidato da Unidad Popular (UP), Salvador Allende, foi um marco fundamental no movimento reformista. "Desejávamos uma universidade cujo único norte fosse o Chile, e os interesses de seu povo. (...) Era um movimento de dignidade nacional e de reflexão sobre a identidade própria" (BRODSKY, 1988, p. 116, tradução nossa).

No governo Allende, muito se avançou no processo de democratização e reforma universitária: se ampliou o acesso à universidade, foram criadas escolas vespertinas, organizações camponesas, indígenas e de trabalhadores, desenvolveram-se programas de extensão que ligavam a universidade à solução de grandes problemas nacionais como saúde, educação, moradia, etc. "A matrícula estudantil se expandiu de um modo impressionante com o apoio massivo estatal, o que possibilitou a criação de novas sedes e cursos: as vagas aumentaram de 22.899 em 1970 a 62.064 em 1972 (até 1980 a cifra havia decrescido a 32.964 vagas)" (ROJAS, 1988, p. 140, tradução nossa). O golpe militar de 1973 não apenas deu início a uma ditadura violenta e responsável por violações massivas aos direitos humanos, perseguindo, torturando e assassinando inúmeros professores e estudantes, como pôs fim a 
todos os avanços democráticos ${ }^{3}$ conquistados durante o movimento reformista da década de 1960.

No Brasil, segundo Fávero (p. 29, 2006), a aceleração do ritmo de industrialização no país na década de 1950, simultaneamente às diversas transformações que ocorreram no campo cultural, social e econômico, levou à tomada de consciência de diversos setores da sociedade sobre a situação precária do ensino público superior brasileiro. De acordo com Martins (2009, p. 17-18), "o período de 1945-65 se destacou por um crescimento acelerado do ensino superior público, (...) suas matrículas saltaram de 21 mil para 182 mil estudantes. Nesse momento, ocorreu o processo de federalização de instituições estaduais e privadas". Nos anos 1960, a onda reformista avançou sobre as universidades brasileiras ${ }^{4}$, tanto por sobre o movimento estudantil, quanto sobre o próprio corpo docente. Os estudantes defendiam a democratização e universalização do ensino, assim como a extinção da cátedra vitalícia, a realização de concursos públicos para a contratação de professores e a ampliação da participação e representação estudantil nos órgãos universitários.

Antes do golpe militar de 1964 no Brasil, algumas universidades elaboraram projetos de reformulação e reestruturação universitária, com destaque para a participação ativa de intelectuais como Darcy Ribeiro e Florestan Fernandes. Na próxima seção, serão expostos o projeto para a educação superior instaurados com os golpes militares no Brasil e no Chile e, posteriormente, as transformações estruturais e subjetivas implementadas nas universidades públicas dos dois países.

\section{AS DITADURAS NO CONE SUL E O PROJETO PARA A EDUCAÇÃO SUPERIOR}

As ditaduras civil-militares no Cone Sul barraram as reformas de base $\mathrm{e}^{5}$ em curso - ou que estavam por acontecer - e implementaram uma série de políticas estruturantes que em muito

\footnotetext{
${ }^{3}$ Em 1972, o gasto em educação alcançou 7,2\% do PIB (CORVALÁN, 2003, p. 26, tradução nossa). Em 1973, o gasto fiscal em educação foi de 4,3\% do PIB, chegando a 2,3\% do PIB em 1990 (AGUILERA, 2015, tradução nossa). Em 2016, o gasto em educação alcançou 5,4\% do PIB chileno (BANCO MUNDIAL).

${ }^{4}$ Entre 1966 e 1982, o gasto em educação no Brasil ficou ao redor de 2,75\% do PIB, chegando a cerca de $4 \%$ nos anos 1990 (PINTO, 2014, p. 300). Em 2015, o gasto em educação alcançou 6,2\% do PIB brasileiro (BANCO MUNDIAL).

${ }^{5}$ No Brasil, o governo de João Goulart (1961-64) propôs uma série de reformas estruturais que não foram aplicadas por conta do golpe de 1964, entre elas: reforma agrária, educacional, fiscal, eleitoral, urbana e bancaria. Já o governo de Allende (1970-73), no Chile, aplicou três reformas de base, que constam entre os principais motivos que levaram ao golpe de 1973: nacionalização das minas de cobre, reforma agrária, educacional, social e de saúde pública.
} 
divergiam das políticas implementadas nos governos anteriores, assim como foram a base para a construção de Estados que preservaram “(...) as extremas desigualdades de classe na distribuição da riqueza pessoal no interior de seu território (...), protegeram a acumulação e o gozo da riqueza oligárquica pelas classes alta e média das exigências e lutas das massas excluídas e exploradas (...)” (ARRIGHI, 1998, p. 234). Para este artigo, nos concentraremos nas reformas educacionais e na subsequente transformação estrutural do ensino superior.

Em vista disso, as figuras de Rudolph Atcon ${ }^{6}$ e dos Chicago Boys, pupilos de Milton Friedman ${ }^{7}$, são importantes para o entendimento de como foram estruturadas as reformas no sistema público no Brasil e no Chile, respectivamente. No início da década de 1960, Atcon realizou um estudo sobre a universidade latinoamericana intitulado La universidad latinoamericana: clave para un enfoque conjunto del desarrollo coordinado social, económico y educativo en America Latina (1961). Nesse trabalho, após uma longa análise sobre a estrutura universitária latino-americana, ele tece algumas recomendações significativas para o entendimento do que vem a ser o conteúdo do Plano Atcon,

A universidade latino-americana deve consolidar sua autonomia e adquirir uma porção muito maior de independência real. $O$ melhor sistema legal para conquistar mais liberdade consiste em transformar a universidade estatal em uma fundação privada. (...) com tal procedimento a universidade deveria ser:

a) Independente legalmente e privada.

b) Financiada por doações anuais do Estado, mais ou menos como se faz na GrãBretanha.

c) Livre de controles e interferências estatais.

d) Completamente dissociada das regulações do serviço civil.

e) Politicamente neutra ${ }^{8}$.

O Plano Atcon foi o documento resultante do estudo de Rudolph Atcon a convite da Diretoria de Ensino Superior do Ministério da Educação e Cultura (MEC), realizado entre junho e setembro de 1965. O documento formulado intitula-se Rumo à Reformulação Estrutural da Universidade Brasileira, e foi editado pelo MEC em 1966. Para sua realização, ele visitou doze universidades brasileiras, quase todas federais, e destacou os aspectos problemáticos das

\footnotetext{
${ }^{6}$ Rudolph P. Atcon (1921-1995), naturalizado estadunidense, atuou junto à Agência dos Estados Unidos para o Desenvolvimento Internacional (USAID) e à Organização dos Estados Americanos (OEA).

${ }^{7}$ Milton Friedman (1912-2006), foi um economista estadunidense e professor na Universidade de Chicago.

8 ATCON, Rudolph. La universidad latinoamericana: Clave para un enfoque conjunto del desarrollo coordinado social, económico y educativo en América Latina. 1961. Bogotá: Christian Hernández Amaya (Edição digital), 2009. Grifo nosso.
} 
universidades, principalmente no que dizia respeito ao sistema de gestão administrativa, sugerindo a implementação de um sistema de administração empresarial.

Dessa forma, Atcon sugere um modelo de reforma universitária no qual, em termos administrativos, a figura do reitor enquanto presidente da instituição, coordena a atuação do Conselho Universitário, que trata dos assuntos da política universitária, e do Conselho de Curadores, que elabora a política financeira da instituição. Entretanto, ele cria a figura do administrador ou gerente, que não deveria ser membro do corpo docente, mas de confiança do reitor e, possuir, segundo Atcon, o mando sobre as unidades centrais da administração institucional, e seus respectivos chefes. Nesse sentido, Atcon (1966, p. 81-82) defendia a implantação de um sistema administrativo tipo "empresa privada" nas universidades brasileiras, pois a autonomia administrativa implicaria na desvinculação da universidade dos controles administrativos e financeiros do Estado. De acordo com Fávero (2006, p. 31), dentre as recomendações feitas está a criação do Conselho de Reitores das Universidades Brasileiras (CRUB), o qual é prontamente criado, em 29 de abril de 1966. Rudolph Atcon é convidado a organizá-lo, além de ser também seu primeiro secretário-geral, entre 1966 e 1968.

Por sua vez, no Chile, já durante a primeira década de intervenção universitária e repressão sistematizada na estrutura legal das instituições, a Junta Militar deu início à transformação estrutural do sistema educacional universitário de caráter neoliberal e autoritário. Essas transformações eram parte da concepção de que a educação tinha que servir aos propósitos do regime e do processo de alojamento do modelo neoliberal no Chile. Nos anos 1950, a partir de um convênio entre a Faculdade de Economia da Universidade Católica de Santiago, a Universidade de Chicago e a Agência dos Estados Unidos para o Desenvolvimento Internacional (USAID), nos Estados Unidos, um grupo de jovens chilenos, conhecidos como Chicago boys, foi estudar na Universidade de Chicago. Os jovens foram alunos e pupilos de Milton Friedman, um economista neoliberal cujo foco de pesquisa e elaboração consistia, fundamentalmente, nas teorias de autorregulação de mercados, equilíbrios macroeconômicos, fortalecimento da iniciativa privada e a promoção da competição através da abertura dos mercados. De volta ao Chile, os Chicago boys ocuparam postos importantes na estrutura governamental da Junta Militar, como mostra a imagem:

Quadro 1 - Os postos chave que os chicago boys ocuparam no governo militar 


\section{Los Chicago boys que ocuparon puestos claves en el gobierno militar}

\begin{tabular}{|c|c|c|c|}
\hline Nombre & Cargos en el gobierno & Cargos en el sector privado & Actividad docente \\
\hline Sergio de Castro & $\begin{array}{l}\text { - Asesor del M. de Economía } \\
\text { - Ministro de Economía } \\
\text { - Ministro de Hacienda }\end{array}$ & $\begin{array}{l}\text { - Asesot de Agustín Edwards } \\
\text { - Ejecutivo de diversas } \\
\text { empresas del grupo Ed wards }\end{array}$ & $\begin{array}{l}\text { - Profesor de jornada } \\
\text { completa en } \\
\text { la U. Católica de Chile }\end{array}$ \\
\hline Pablo Baraona & $\begin{array}{l}\text { - Asesor del M. de Agricultura } \\
\text { - Presidente del Banco Central } \\
\text { - Ministro de Economía } \\
\text { - Ministro de Minería }\end{array}$ & $\begin{array}{l}\text { - Presidente del Banco Unido } \\
\text { de Fomento (liquidado) } \\
\text { - Presidente del Club Hípico } \\
\text { - Jefe de la campafia } \\
\text { presidencial de Hernán Büchi }\end{array}$ & $\begin{array}{l}\text { - Profesor de jornada } \\
\text { completa en } \\
\text { la U. Católica de Chile }\end{array}$ \\
\hline Alvaro Bardon & $\begin{array}{l}\text { - Funcionario de Corfo } \\
\text { - Presidente del Banco Central } \\
\text { - Subsecretario de Economía } \\
\text { - Presidente del } \\
\text { Banco del Estado }\end{array}$ & $\begin{array}{l}\text { - Presidente del Banco } \\
\text { Concepción } \\
\text { - Socio Consultora Gemines } \\
\text { - Presidente del Centro } \\
\text { Democrático Libre }\end{array}$ & $\begin{array}{l}\text { - Diréctor del Dpto. } \\
\text { de Economía de } \\
\text { la U. de Chile }\end{array}$ \\
\hline Rolf Lüders & $\begin{array}{l}\text { - Biministro de Hacienda } \\
\text { y Economía }\end{array}$ & $\begin{array}{l}\text { - Asesor de Javier Víal } \\
\text { - Ejecutivo y socio } \\
\text { de las empresas del ex BHC }\end{array}$ & $\begin{array}{l}\text { - Profesor de jornada } \\
\text { completa en } \\
\text { la U. Católica de Chile }\end{array}$ \\
\hline
\end{tabular}

Fonte: Memória chilena. Disponível em: <http://www.memoriachilena.cl/602/w3-article-86239.html>.

Este modelo de Estado capitalista “(...) caracteriza-se pela fragmentação de todas as esferas da vida social, partindo da fragmentação da produção, da dispersão espacial e temporal do trabalho, da destruição dos referenciais que balizavam a identidade de classe e as formas de luta de classes" (CHAUI, 2003, p. 7). Consequentemente, a universidade teve de ser adaptada à essa visão organizacional e fragmentada, como ressalta Chaui (2003, p. 7), passando a ser avaliada por índices de produtividade, organizada para ser flexível e possuir eficácia de gestão, "definida e estruturada por normas e padrões inteiramente alheios ao conhecimento e à formação intelectual, (...) pulverizada em micro-organizações que ocupam seus docentes e curvam seus estudantes a exigências exteriores ao trabalho intelectual" (Id). A universidade pública, voltada à produtividade e produção de conhecimento útil ao capital, tem suas pesquisas determinadas pelas exigências mercadológicas; "isso significa que a universidade pública produz um conhecimento destinado à apropriação privada" (CHAUI, 2003, p. 8).

Consequentemente, a implementação do modelo neoliberal baseado na doutrina monetarista de Milton Friedman, através do que ficou conhecido como o "Experimento de Chicago", produziu "(...) o desmantelamento de um dos sistemas universitários mais fecundos e democráticos em todas as Américas." (AUSTIN, 2004, p. 189, tradução nossa). Apresentadas as concepções norteadoras dos distintos projetos para o ensino superior implementados pelos governos militares em consonância com as aspirações de parte do empresariado e das elites 
econômicas brasileiras, chilenas e internacionais, nas próximas sessões serão analisados os marcos jurídicos e políticos desse processo de transformação no Brasil e no Chile, respectivamente.

\section{BRASIL: A REFORMA UNIVERSITÁRIA DE 1968}

O golpe civil-militar no Brasil e os seguintes vinte e um anos de ditadura serviram, entre outras coisas, para proteger os interesses oligárquicos e burgueses nacionais e internacionais, com orientação da política externa estadunidense que visava garantir o domínio geopolítico e econômico sobre a região. No âmbito educacional, a ditadura civil-militar brasileira promoveu duas reformas: a Reforma Universitária em 1968 (Lei 5.540/68) e a da educação geral em 1971, através da Lei de Diretrizes e Bases da Educação Nacional (Lei $5.692 / 71)^{9}$.

Nos meses posteriores ao golpe, “(...) o governo fez uso, em vários órgãos do setor público, de medidas repressivas, denominadas 'operação limpeza', as quais visavam a depurar essas instituições de funcionários e servidores, suspeitos de estarem comprometidos com 'atividades subversivas"” (CUNHA, 2009, p. 129). Para tal, foram instaladas Comissões Especiais de Investigação Sumária (CEIS) que, segundo Cunha (Id., p. 130), eram compostas de professores, reitores e funcionários das Universidades e que serviram para efetivar o expurgo destes professores, estudantes ou funcionários. Em relação ao movimento estudantil, a sede da União Nacional dos Estudantes (UNE) foi invadida e incendiada logo após o golpe, assim como diversas entidades de representação estudantil pelo país.

Institucionalmente, a Lei Suplicy de Lacerda (Lei 4.464/64) - chamada assim por causa do nome do ministro da Educação, Eduardo Suplicy de Lacerda - proferiu o golpe que clausurou as instituições de representação estudantil, extinguindo a UNE (que continuou atuando na clandestinidade) e estabelecendo regras sobre os órgãos de representação que viriam a ser criados, como os Diretórios Acadêmicos (DAs) e Diretórios Centrais dos Estudantes (DCEs). Segundo Cunha (2009, p. 130), a Lei Suplicy foi revogada em 1967 por um novo Decreto, o Decreto Aragão (Decreto-Lei no 228) - chamado assim em razão do nome do

\footnotetext{
${ }^{9}$ BOSCHETTI, Vania Regina. Plano Atcon e Comissão Meira Mattos: construção do ideário da Universidade do pós-64. Revista Histedbr On-line, Campinas, n. 27, p.221-229, set. 2007.
} 
ministro da Educação Raymundo Moniz de Aragão - que restringiu ainda mais a participação estudantil nas universidades e estabeleceu eleições indiretas para os DCEs.

Também na década de 1960, foram firmados os doze acordos MEC/USAID. Na esteira da Aliança para o Progresso ${ }^{10}$, a USAID interviu na América Latina de maneira a prover assistência técnica, financeira e militar, bem como fornecer equipamentos militares (FÁVERO, 2006, p. 30). No campo da educação, o vínculo com a USAID se deu através da assinatura de dois convênios de cooperação técnica para o aperfeiçoamento dos níveis de ensino entre a agência e o Ministério da Educação e Cultura (MEC). A realização dos Acordos provocou diversas manifestações estudantis contrárias aos convênios. Inclusive, a UNE organizou em 1967, já na clandestinidade, seminários com o intuito de formular um "programa de lutas" contra a intervenção ideológica e prática dos Estados Unidos na reformulação do ensino superior brasileiro.

Segundo Cunha (2009, p. 133), os acordos tinham como finalidade a ampliação e reestruturação do ensino superior num prazo de cinco anos e a criação de um quadro de técnicos em planejamento educacional, designado Equipe de Assessoria ao Planejamento do Ensino Superior (EAPES), que deveriam atuar até 1969, ano em que foi publicado pelo MEC o Relatório da EAPES. Em resumo, o relatório abordava os seguintes tópicos: “(...) aumento e diversificação dos recursos destinados para a educação; revisão do critério de gratuidade do ensino universitário; estímulo de criação de universidades particulares; (...) transformação das universidades federais em fundação" (CUNHA, 2009, p. 134).

Nos anos 1966 e 1967 houve um agravamento da crise nas universidades e os protestos do movimento estudantil tornaram-se mais intensos. Assim, o governo criou, por meio do Decreto $\mathrm{n}^{\mathrm{o}}$ 62.024/67, a Comissão Especial para Assuntos Estudantis, conhecida como Comissão Meira Mattos, pois era presidida pelo general Carlos de Meira Mattos, membro da Escola Superior de Guerra. A comissão tinha a finalidade de emitir pareceres sobre as atividades estudantis, propor medidas que possibilitassem melhor aplicação das diretrizes governamentais no setor estudantil e supervisionar a execução dessas diretrizes (FÁVERO, 2006, p. 31). Além disso, o relatório propunha soluções para o problema dos "excedentes", decorrente da falta de vagas para todos os candidatos aprovados nos vestibulares; da reforma universitária e da

\footnotetext{
${ }^{10}$ Programa de ajuda econômica e social, proposto por John F. Kennedy em 1961, para apoiar medidas reformistas nos países latino-americanos e fortalecer os setores fiéis às políticas dos EUA, para determinar sua zona de influência hemisférica e conter o avanço revolucionário.
} 
estrutura do MEC. As soluções envolviam o "fortalecimento do princípio de autoridade e disciplina (...); ampliação de vagas; implantação do vestibular unificado; criação de cursos de curta duração e ênfase nos aspectos técnicos e administrativos” (Id., p. 32).

Também em 1966 e 1967, foram promulgados os Decretos-Lei no 53/66 e no 252/67. O primeiro estabelecia a integração do ensino e da pesquisa nas unidades universitárias e a exigência de que as universidades federais apresentassem ao MEC e ao Conselho Federal de Educação seus planos de reestruturação, transformados posteriormente em estatutos adaptados à nova lei. O segundo, complementar ao Decreto-Lei no 53/66, estabelecia a criação dos departamentos enquanto frações menores da estrutura universitária.

No ano de 1968, em resposta à crise nas universidades e intensa mobilização estudantil, o governo criou o Grupo de Trabalho para a Reforma Universitária (GTRU), através do Decreto ${ }^{\circ}$ 62.937, em julho de 1968. O GTRU tinha um prazo de 30 dias para elaborar um projeto de Reforma Universitária baseando-se nos relatórios apresentados pela EAPES, Rudolph Atcon e a Comissão Meira Mattos. Por fim, as propostas apresentadas pelo GRTU englobavam, entre outras medidas: a adoção do ciclo básico e do ciclo profissionalizante; a admissão dos regimes jurídicos de autarquia, fundação ou associação; a adoção da matrícula por disciplinas, do sistema de créditos e do regime de centros e departamentos; a utilização do vestibular eliminatório como forma de ingresso; a extinção da cátedra vitalícia; o princípio da dedicação exclusiva.

A lei da reforma universitária ${ }^{0} 5.540 / 68$, de caráter modernizador e autoritário ${ }^{11}$, foi aprovada no final de novembro de 1968. Florestan Fernandes (1975, p. 4) observa que a insuficiência do Relatório do GRTU em resolver os problemas do ensino superior brasileiro “é parte normal de uma situação histórico-social em que a atuação conservadora se acha ameaçada

\footnotetext{
${ }^{11}$ Observando o quadro geral, pode-se dizer que o propósito modernizador se concentrava na perspectiva econômica e administrativa, com vistas ao crescimento, à aceleração da industrialização e à melhoria da máquina estatal. Já o projeto autoritário-conservador se pautava em manter os segmentos subalternos excluídos, especialmente como atores políticos, bem como em combater as ideias e os agentes da esquerda - por vezes, qualquer tipo de vanguarda - nos campos da política e da cultura, defendendo valores tradicionais como pátria, família e religião, incluindo a moral cristã [...]. Da estrutura departamental ao sistema de pós-graduação, passando pelos exames vestibulares [...], a base da estrutura universitária em vigor foi construída sob a ditadura; [...]. No eixo conservador, o regime militar combateu e censurou as ideias de esquerda e tudo mais que achasse perigoso e desviante - e, naturalmente, os defensores dessas ideias -; controlou e subjugou o movimento estudantil; criou as ASI (Assessorias de Segurança e Informação) para vigiar a comunidade universitária; censurou a pesquisa, assim como a publicação e circulação de livros; e tentou incutir valores tradicionais por meio de técnicas de propaganda, da criação de disciplinas dedicadas ao ensino de moral e civismo e de iniciativas como o Projeto Rondon (MOTTA, 2014, p. 22-23).
} 
e é compelida a assumir o controle político dos processos de modernização cultural e de inovação institucional’. Segundo Motta (2014, p. 22-23),

\begin{abstract}
No que toca especificamente às universidades, a modernização conservadora implicou: racionalização de recursos, busca de eficiência, expansão de vagas, reforço da iniciativa privada, organização da carreira docente, criação de departamentos em substituição ao sistema de cátedras, fomento à pesquisa e à pós-graduação. Para viabilizar a desejada modernização, sobretudo durante o período inicial do regime militar (1964-68), enfatizou-se a adoção de modelos universitários vindos dos países desenvolvidos, em particular dos Estados Unidos [...]. As universidades representam espaço privilegiado para observar os entrechoques das diferentes forças que moveram o experimento autoritário brasileiro. Elas eram importantes lócus de modernização do país, bem como campo de batalha entre os valores conservadores e os ideais de esquerda e de vanguarda; eram instituições que o regime militar, simultaneamente, procurou modernizar e reprimir, reformar e censurar.
\end{abstract}

Em 1969 foi promulgado o Decreto-Lei no 464/69 que, segundo Cunha (p. 149, 2009), condicionava o funcionamento das universidades às exigências do mercado de trabalho, exigia a implementação do ciclo básico prévio ao ciclo profissionalizante e estabelecia um prazo de 90 dias para que as universidades encaminhassem ao Conselho Federal de Educação seus estatutos adaptados à lei da Reforma Universitária. O ciclo básico e o vestibular unificado serviam para a racionalização do preenchimento das vagas, pois a admissão não era mais para determinado curso e, sim, para determinada área de conhecimento. Passados os três semestres de ciclo básico, os estudantes realizavam um "segundo vestibular" interno e, dependendo de sua pontuação, escolhiam o curso profissionalizante. Ambas soluções se mostram problemáticas logo depois, uma vez que criaram o problema do "excedente interno": estudantes que não conseguiam vaga no curso escolhido do ciclo profissionalizante, principalmente os mais requisitados. Nesse sentido, o clima de competição interna gerado entre os estudantes, somado à desmobilização do movimento estudantil por parte dos militares, serviu como combustível para o desenvolvimento da universidade enquanto espaço onde valorizava-se a alta produtividade e o rendimento.

O sistema departamental que organizou e congregou professores por disciplinas e pesquisas afins, por sua parte, deu origem a “(...) um espaço de alocação burocráticoadministrativa de professores, tornando-se, em alguns casos, elemento limitador e até inibidor de um trabalho de produção de conhecimento coletivo" (FÁVERO, 2006, p. 34). Assim como a departamentalização, foram implementados o sistema de créditos e a matrícula por disciplina, que permitiam a racionalização dos recursos da universidade. 


\section{CHILE: REFORMA UNIVERSITÁRIA NEOLIBERAL E AUTORITÁRIA}

No Chile, o golpe de Estado que destituiu o governo democraticamente eleito de Salvador Allende no dia 11 de setembro de 1973, marcou o início de uma ditadura militar que durou 17 anos (1973-1990). Nos primeiros anos da ditadura, que teve como chefe da Junta Militar o general Pinochet, a perseguição política foi intensa; inúmeros estudantes, professores e servidores das universidades do país foram torturados, exonerados, expulsos, exilados, torturados ou presos. Tais práticas de perseguição, inquérito e violência tinham como objetivo a eliminação de quaisquer suspeitos que fossem considerados "subversivos". Todas as organizações e órgãos democráticos de representação estudantil foram fechados no mesmo dia do golpe e substituídos por federações construídas pelo regime militar e seus aliados estudantis; seus bens e patrimônio foram apreendidos e seus líderes perseguidos. Além disso, a ditadura chilena iniciou uma campanha de desprestígio de todas as reformas promovidas durante o governo de Allende, entre elas, a Reforma Universitária.

Ainda durante esse período, iniciou-se um processo de intervenção e institucionalização do golpe na estrutura universitária. Através da promulgação dos DecretoLei $\mathrm{n}^{\mathrm{o}} 50$ e 111 , de $1^{\circ}$ e 29 de outubro de 1973, respectivamente, o ditador Augusto Pinochet foi aclamado patrono da Universidade e institucionalizou-se a intervenção universitária através da centralização do poder na figura do Reitor-Delegado, designado pela Junta Militar. À figura do Reitor-Delegado foi concedido o poder de suprimir e criar cargos, aplicar sanções (expulsão, suspensão, etc.) aos estudantes, transferir funcionários a outras sedes, contratar ou finalizar contratos sem considerar prazos legais, entre outras atribuições (ORELLANA, 2016, p. 56).

A intervenção nas universidades chilenas ocorreu dentro do espectro da concepção de que a educação deveria servir aos propósitos do regime e ao processo de alojamento do modelo neoliberal no Chile. Em 1975, o Ministério da Educação publicou as chamadas Políticas Educacionales del Gobierno de Chile, as quais deram início ao processo de desmantelamento do sistema público universitário. Essas políticas sinalizaram o que veio a concretizar-se nos anos 1980: o término da gratuidade do ensino público superior. "Instituiu-se, no curto prazo, uma 'matrícula diferenciada por eixos', na qual cada um paga de acordo com suas capacidades econômicas, pessoais e familiares e que, em 1977, transforma-se no pagamento de uma tarifa 
diferenciada, no contexto da política de autofinanciamento" (ESPEJO, 2012, p. 82-83, tradução nossa).

As universidades chilenas não escaparam à adoção do modelo neoliberal e, em pouco tempo, sofreram reduções no orçamento anual, diminuição da quantidade de professores e da oferta de matrículas. A Reforma Universitária do governo Allende "havia removido a mística da educação superior como brinquedo das elites" (HENRY, 2004, p. 201, tradução nossa), enquanto o golpe, orquestrado por interesses internacionais em conjunto com as oligarquias nacionais, buscou a restauração do privilégio das elites, sendo a universidade parte fundamental desse privilégio. O modelo neoliberal e autoritário pressupunha também a "neutralidade política" como base para a educação, que se converteu em uma educação muito mais técnica, promovendo a reestruturação dos currículos para que fossem adequados à uma concepção mercadológica de educação.

Como aponta Henry (2004, p. 204, tradução nossa), a diminuição do número de matrículas significou o distanciamento da educação superior em relação às classes campesina e trabalhadora, a mudança no perfil dos estudantes, que passaram a ser mais conservadores e elitistas, e a despolitização da vida diária no campus. O novo modelo político econômico do Estado requeria que a Universidade gerasse mão de obra, com o objetivo único de satisfazer a demanda do mercado para questões técnicas e comerciais.

Um outro momento simbólico no processo de desmonte da educação pública chilena foi o pronunciamento da Directiva Presidencial sobre Educación Nacional em 1979. No mesmo ano em que foi promulgado o Decreto $n^{\circ}$ 18.962/1979 que estabeleceu a transferência de estabelecimentos técnico-profissionais às empresas privadas. A Directiva Presidencial condicionou ideologicamente o modelo educacional da ditadura a partir de quatro pontos principais, entre eles:

1. Estado subsidiário: o fim da responsabilidade fiscal do Estado, que produziu a perda geral da gratuidade na educação universitária que existia desde o Século XIX.

2. Abertura da educação superior ao livre mercado: princípio que gerou o processo de privatização das universidades e que deu condições para que a educação superior fosse considerada nos moldes de uma empresa privada, através da demanda de eficiência no produto (formação) e da capacidade de autofinanciar-se. 
3. Doutrina de Segurança Nacional: o pretexto basilar para a repressão e a supressão do pensamento crítico, que expulsou das universidades não apenas professores, estudantes e servidores, como livros, materiais, publicações e pesquisas consideradas marxistas e subversivas.

4. Descentralização: a desintegração das universidades estatais nacionais, como a Universidad de Chile e a Universidad Técnica del Estado (atualmente Universidad de Santiago de Chile), que passaram a ser universidades metropolitanas.

O golpe mais forte sofrido pelo ensino superior chileno ocorreu a partir da promulgação da Ley General de las Universidades em 1981, que “(...) criou as universidades privadas e começou a cobrar tarifas de todos os estudantes, o que terminou com a histórica gratuidade da educação no Chile” (MORAGA, 2012, p. 32, tradução nossa). Como indicado na Directiva Presidencial de 1979, a partir de 1981, os estudantes passaram a pagar montantes iguais de tarifa e matrícula, sem diferenciações socioeconômicas. A partir disso, a responsabilidade estatal quanto ao financiamento das instituições universitárias foi praticamente extinta, recaindo sobre as próprias universidades a obrigação de autofinanciar-se através da cobrança de tarifas e matrículas. O endividamento estudantil passou a ser parte da realidade de muitos dos estudantes que ingressaram no ensino superior. E os professores tiveram sua remuneração reduzida em mais de 50\% durante a ditadura, como afirma Austin (2004, p. 230, tradução nossa). Ainda, a Ley General de Universidades promoveu:

- A limitação da autonomia universitária (Artigos 3, 4, 5, 6, 7 e 8)

- A exclusão da política partidária como expressão possível dentro das Universidades (Artigo 6)

- O estabelecimento de um conjunto de Títulos Profissionais que somente podem desenvolver-se dentro das universidades já que necessitariam da obtenção do Grau Acadêmico de Licenciado (Artigos 11, 12 e 13)

- Proibição da participação dos funcionários administrativos e estudantes na definição da gestão e definição da direção destas novas Universidades (Artigo 24)

Além disso, foi dado início ao desmembramento da Universidade do Chile (UCH) e da Universidade Técnica do Estado (UTE), para a criação de novas Universidades Estatais a partir das sedes regionais que estas instituições tinham. Nesse sentido, a gama das Universidades Estatais se diversifica a partir da eliminação da presença do caráter nacional que estas duas instituições tinham no país. Essas sedes regionais foram transformadas diretamente ou fundidas com outras sedes, para dar lugar às novas Universidades Estatais (GARRIDO, 2015, p. 331-332, tradução nossa). 
O desmonte do ensino público superior teve como efeito direto o incentivo à proliferação de instituições superiores privadas ${ }^{12}$ tecnicistas e mercantilistas. "De fato, nada menos que 50 institutos profissionais e 75 centros de formação técnica foram inaugurados em Santiago durante os anos 1980-1993, vinculados ao capital internacional e corporações como Epson, Manpower, Esucomex, Gamma e Canon" (AUSTIN, 2004, p. 224, tradução nossa). Inclusive, o conjunto de leis imposto entre 1979 e 1981 estabeleceu que qualquer empresário poderia abrir uma instituição de ensino superior. Segundo Garrido (2015, p. 333, tradução nossa), "o aumento da quantidade de universidades no Chile se realizou com base no convencimento em relação aos supostos benefícios que teria uma presença maior da iniciativa privada na outorga de possibilidades educativas à população".

As mudanças estruturais no caráter do sistema educacional público chileno foram implementadas até, literalmente, o último dia de exercício da Junta Militar, quando foi publicada a Ley Orgánica Constitucional de Enseñanza (LOCE), Lei n ${ }^{\circ} 18.962$, de 10 de março de 1990. A lei reiterou os princípios de segurança nacional, livre mercado, liberdade econômica de ensino e de abertura de estabelecimentos, e de restrição ideológica. Segundo Moreno-Doña e Jiménez (2014, p. 59), é importante salientar que a LOCE operou como um "enclave autoritário" da ditadura, pois requeria um alto quórum em ambas as câmaras do Congresso Nacional para sua modificação. A LOCE foi revogada apenas no ano de 2009, quando foi então promulgada a Ley General de Educación (LGE).

Apesar de os governos da concertación pós-redemocratização terem realizado mínimas mudanças no sistema de ensino superior chileno, a estrutura das universidades permaneceu praticamente inalterada (MORENO-DOÑA, JÍMENEZ, 2014, p. 58, tradução nossa). “(...) Segundo dados da OCDE para o ano de 2013, a média de custo para os estudantes universitários chilenos é uma das mais caras a nível mundial, chegando a US\$6.000 anuais” (GARRIDO, p. 336, 2015, tradução nossa). O movimento estudantil chileno, fortemente reprimido durante a ditadura, reemerge na década de 1980 e, posteriormente, na

\footnotetext{
${ }^{12}$ A partir dessas transformações se passa do cenário de 1981, composto por 8 universidades (2 estatais e 6 privadas), a um cenário totalmente diferente, onde na atualidade existem 60 universidades diferenciadas segundo duas grandes tipologias: 1) Universidades pertencentes ao Consejo de Rectores de las Universidades Chilenas (CRUCH): a. Universidades Estatales: 16 universidades que se originam do desmembramento da UCH e da UTE; b. Universidades privadas tradicionais: 9 universidades que correspondem às 6 universidades privadas criadas antes de 1981 e outras que nasceram a partir destas. 2) Universidades privadas: 35 universidades fundadas posteriormente a 1981. São de uma alta variedade, algumas são propriedade de grupos acadêmicos, empresariais, políticos e religiosos diferenciados, e além disso, outras pertencentes a transnacionais dedicadas ao negócio educacional. (GARRIDO, 2015, p. 333, tradução nossa).
} 
redemocratização do país como uma força fundamental de resistência, protagonizando diversos levantes massivos como a Revolução dos Pinguins ${ }^{13}$, em 2006, e a grande onda de manifestações estudantis nos anos de 2011 e $2012^{14}$. Em janeiro de 2018, o Congresso do Chile aprovou a Lei do Ensino Superior, que estabelece a gratuidade universal progressiva. Essa lei é parte da Reforma Educacional que vinha sendo gestada na gestão da presidenta Michelle Bachelet. No mesmo dia, foi aprovado o projeto de lei sobre universidades estatais, que devolve ao Estado a responsabilidade em assegurar a educação superior pública e gratuita.

\section{CONSIDERAÇÕES FINAIS}

Na década de 1960, na América Latina, a conjuntura política dos países e da região proporcionou a criação de espaços de debates políticos fundamentais em setores diversos, tais como saúde pública, educação pública, reforma agrária, entre outros. No Chile, o movimento pela reforma universitária, levado a cabo durante o governo Allende, mobilizou os estudantes de todo país no que dizia respeito à democratização, universalização e ampliação do ensino superior público. No Brasil, a luta pela reforma universitária também foi protagonizada pelo movimento estudantil. Contudo, as iniciativas de promoção das reformas por parte das universidades brasileiras foram interrompidas com o golpe civil-militar em 1964. Também no Chile, o golpe de 1973 barrou as transformações promovidas pela reforma universitária do governo Allende e iniciou uma campanha de desprestígio nacional da mesma.

As ditaduras civil-militares brasileira e chilena promoveram reformas na educação superior pública como parte de seus projetos de governo e de país a serviço do capital internacional, ainda que em caráter distinto e com resultados também distintos. Nos anos iniciais, além da elaboração dos planos e projetos de reforma, os regimes autoritários foram responsáveis por perseguições, prisões e desaparecimentos nas universidades e estabelecimentos públicos de ensino como forma de reprimir qualquer tipo de força de oposição contra o governo. No Brasil, a Reforma de 1968 foi de caráter modernizador e autoritário, ou seja, enquanto de um lado a dita modernização implicou em medidas orientadas ao crescimento

\footnotetext{
13 A "revolução dos pinguins" foi um movimento dos estudantes secundaristas chilenos em 2006, apelidados pinguins por causa de seus uniformes (paletó e gravata). Mais de 600 mil estudantes aderiram a uma greve geral pelo passe-livre e pela reforma da LOCE (1990).

${ }^{14}$ Ver "Protestos no Chile - Onda de manifestações estudantis sacode o país" (UOL, 2011), disponível em: $<$ https://vestibular.uol.com.br/resumo-das-disciplinas/atualidades/protestos-no-chile-onda-de-manifestacoesestudantis-sacode-o-pais.htm>. Acesso em: 20 de jul. 2019.
} 
e aceleração da industrialização, o projeto conservador e autoritário se pautava no combate aos agentes "subversivos", na defesa da pátria, da família e da religião (MOTTA, 2014, p. 22). Assim, a Reforma instituiu uma concepção muito similar à concepção norte-americana de educação voltada para o mercado, provocando uma reestruturação do ensino público e da estrutura universitária no sentido da racionalização de recursos, busca por eficiência e fortalecimento da iniciativa privada.

Como foi apresentado neste trabalho, o caso chileno demonstra que o governo ditatorial da Junta Militar presidida por Augusto Pinochet concebia a educação superior como um pilar fundamental para a nova concepção de Estado neoliberal subsidiário orientada pelos Chicago boys. Nesse sentido, foram promulgadas diversas leis que transformaram profundamente a relação do Estado com a educação superior, no sentido de sua transformação neoliberal e autoritária. A organização da educação como um mercado abriu caminhos para a crescente participação de agentes privados no sistema educacional e a privatização das universidades, além de romper com o processo historicamente construído da gratuidade na educação superior pública, integração social e sistema nacional de educação, aprofundados durante o mandato de Salvador Allende, nos quais o Estado tinha um papel fundamental.

Apesar de compartilharem de um fundo comum em relação a concepção mercadológica de educação, com incentivos às parcerias público-privadas, melhora na eficiência administrativa e aumento da produtividade, no caso brasileiro, apesar das diversas transformações na estrutura universitária, como a implementação do sistema de créditos e da departamentalização das faculdades dentro da concepção de universidade orientada por Rudolph Atcon e pela USAID, não foi instituída a cobrança de mensalidades nas universidades públicas. Isso se deveu em parte à organização de resistência popular, principalmente do movimento estudantil e docente, mas também ao caráter próprio da universidade enquanto espaço de disputa entre as diferentes forças conservadoras e autoritárias e modernizadoras que atuavam no regime.

Faz-se fundamental compreender as ditaduras civil-militares brasileira e chilena, assim como as outras ditaduras do Cone Sul, como processos políticos que não ocorreram de maneira independente ao contexto global de Guerra-Fria e disputa nos campos ideológico, político e econômico pela ampliação da esfera de influência do capitalismo internacional na América Latina, por parte dos Estados Unidos. Nesse contexto, a educação era entendida como um campo fundamental dentro do conceito de Ditadura de Segurança Nacional, tanto no que diz 
respeito à eliminação da oposição nas universidades, quanto pela garantia da associação ao capital internacional na reestruturação das universidades dentro desse propósito. Sobretudo no Chile, a ditadura de Pinochet concebia a educação, em seu caráter pedagógico, como meio de transmissão dos interesses e da ideologia das classes dominantes para garantir a dominação das demais classes, tanto através da repressão, visto que a classe dominante detém o monopólio legal da violência, quanto através do sistema de ensino e da concepção educacional hegemônica. E, por outro lado, a educação superior era entendida como primordial para a expansão econômica, ou seja, a educação compreendida como garantia de produtividade (aumento da capacidade produtiva do país como forma de negar a condição de subdesenvolvimento) e oferta de mão de obra, justificando a participação, ainda que reduzida, do Estado chileno em seu financiamento.

O presente trabalho não dá conta de tecer extensas análises acerca das transformações na estrutura do ensino superior público do Brasil e do Chile, ocorridas durante as ditaduras que marcaram a segunda metade do século XX. Entretanto, busca apresentar um panorama das principais alterações estruturais de caráter modernizador e autoritário, no Brasil, e neoliberal e autoritário, no Chile. Por isso, conclui-se que a realidade atual do ensino superior, um pilar importante para a produção de ciência e tecnologia a serviço dos projetos políticos e econômicos das ditaduras, deve ser analisada de maneira a considerar seus processos históricos e sociais de reestruturação, reformas e transformações.

\section{REFERÊNCIAS}

AGUILERA, Natalia Slachevsky. Una revolución neoliberal: la política educacional en Chile desde la dictadura militar. Educ. Pesqui., São Paulo, v. 41, n. spe, p. 1473-1486, dez. 2015. Disponível em $\quad<$ http://www.scielo.br/scielo.php?script=sci_arttext\&pid=S151797022015001001473\&lng=es\&nrm=iso>. Acesso em

jul. 2019. http://dx.doi.org/10.1590/S1517-9702201508141660.

ARRIGHI, Giovanni. A ilusão do desenvolvimento. 6. ed. Petrópolis/RJ: Editora Vozes, 1998. $188 \mathrm{p}$.

ATCON, Rudolph. La universidad latinoamericana: Clave para un enfoque conjunto del desarrollo coordinado social, económico y educativo en América Latina. 1961. Bogotá: Christian Hernández Amaya (Edição digital), 2009. 
ATCON, Rudolph. Rumo à reformulação estrutural da universidade brasileira. Rio de Janeiro: MEC/DES, 1966.

AUSTIN, Robert Henry (Comp.). Intelectuales y Educación Superior en Chile: De la independencia a la democracia transicional 1810-2001. Santiago: Ediciones Chile y América CESOC, 2004.

BANCO MUNDIAL. Gasto público en educación, total (\% del PIB). Disponível em: <https://datos.bancomundial.org/indicador/SE.XPD.TOTL.GD.ZS>. Acesso em: 10 jul. 2019.

BOSCHETTI, Vania Regina. Plano Atcon e Comissão Meira Mattos. Histedbr Online, Campinas, n. 27, p.221-229, set. 2007.

CHAUI, Marilena. A universidade pública sob nova perspectiva. Revista Brasileira de Educação, Rio de Janeiro, n. 24, p. 5-15, Dez. 2003.

CORVALÁN, Luis. El Gobierno de Salvador Allende. Santiago: LOM Ediciones, 2003.

CUNHA, Janaína Dias. A Reforma Universitária de 1968 e o processo de reestruturação da UFRGS (1964-1972): uma análise da política educacional para o ensino superior durante a ditadura civil-militar brasileira. 2009. 213 f. Dissertação (Mestrado) - Curso de Programa de Pós-graduação em Educação, Universidade do Vale do Rio dos Sinos, São Leopoldo, 2009.

FÁVERO, Maria de Lourdes de Albuquerque. A universidade no Brasil: das origens à Reforma Universitária de 1968. Educar, Curitiba, n. 28, p.17-36, 2006.

FEDERACIÓN UNIVERSITARIA DE CÓRDOBA. La juventud argentina de Córdoba a los hombres libres de Sudamérica [Manifiesto de Córdoba]. Argentina, junho de 1918.

FERNANDES, Florestan. Universidade Brasileira: Reforma ou Revolução. São Paulo, AlfaÔmega, 1975.

FREITAS NETO, José Alves de. A reforma universitária de Córdoba(1918): um manifesto por uma universidade latino-americana. Revista Ensino Superior Unicamp, Campinas, v. 3, n. 1, p. 62-70, jun/set. 2011.

GARRIDO, Felipe Andres Zurita. EL SISTEMA UNIVERSITARIO EN EL CHILE CONTEMPORÁNEO. Educ. rev., Belo Horizonte, v. 31, n. 2, p. 329-343, Junho 2015. 
HERRERA, Felipe; LJUBETIC, Yerko; ROVIRA, Gonzalo; ROJAS, Alejandro; MARTÍNEZ, Fernando; QUINTANA, Germán; TOHÁ, Carolina. In: BRODSKY, Ricardo (Org.). Conversaciones con la FECH. Santiago: Edit. Chile y América, 1988.

MARTINS, Carlos Benedito. A Reforma Universitária de 1968 e a abertura para o ensino superior privado no Brasil. Educação \& Sociedade, Campinas, v. 30, n. 106, p.15-35, jan./abr. 2009.

MORENO-DOÑA, Alberto; JIMÉNEZ, Rodrigo Gamboa. Dictadura Chilena y Sistema Escolar: "a otros dieron de verdad esa cosa llamadal educación”. Educar em Revista, Curitiba, v. 51, n. 1, p.51-66, mar. 2014.

MOTTA, Rodrigo Patto Sá. A ditadura nas universidades: repressão, modernização e acomodação. Cienc. Cult., São Paulo , v. 66, n. 4, p. 21-26, Dez. 2014. Disponível em $<$ http://cienciaecultura.bvs.br/scielo.php?script=sci_arttext\&pid=S0009-

67252014000400010\&lng=en\&nrm=iso>. Acesso em 20 de julho de 2019. http://dx.doi.org/10.21800/S0009-67252014000400010.

PINTO, José Marcelino de Rezende. O Golpe de 1964 e o financiamento: ditaduras não gostam de educação. RBPAE, Porto Alegre, v. 30, n. 2, p.287-301, maio/ago. 2014. Disponível em: <https://seer.ufrgs.br/rbpae/article/viewFile/53677/33091>. Acesso em: 10 jul. 2019.

SALAZAR, Gabriel; DÍAZ, Pilar; MORAGA, Gabio; MUÑOZ, Víctor; CISTERNAS, Leonardo; TOLEDO, Natalia; VENEGAS, Martina; MOLINA, Fernando; ESPEJO, Camila; DÍAZ, Viviana. In: CISTERNAS, Leonardo (Comp.). Archivo, memoria y movilización: Archivo de la Federación de Estudiantes de la Universidad de Chile. Santiago: Archivo y Centro de Documentación FECH, 2012, 159 p.

ZERAN, Faride; PÓO, Ximena; NASH, Claudio; ORELLANA, Macarena; CANDINA, Azun; DORFMAN, Ariel; VALENZUELA, Berta; JARA, Isabel; PALMA, Eric Eduardo; REBOLLEDO, Loreto; GUERRERO, Manuel; GNECCO, Gilda; BIANCHI, Soledad; BRUGNOLI, Francisco. In: PÓO, Ximena (Ed.). La ditadura de los sumários (1974-1985): Universidad de Chile intervenida. Santiago: Editorial Universitaria, 2016, 320 p. 
